OPEN ACCESS

Edited by:

Roberto Pola,

Università Cattolica del Sacro

Cuore, Italy

Reviewed by:

labal Haider Jaffer,

McMaster University, Canada

Alberto Tosoni,

Agostino Gemelli University

Polyclinic, Italy

Giovanni Addolorato,

The Catholic University of America,

Italy

*Correspondence:

Antonio Mirijello

a.mirijello@operapadrepio.it

Specialty section:

This article was submitted to

Thrombosis,

a section of the journal

Frontiers in Cardiovascular Medicine

Received: 25 May 2021 Accepted: 26 August 2021 Published: 04 October 2021

Citation:

Mirijello A, Santoliquido M, Piscitelli P.

Borelli C, Serviddio G, Simeone A, Grandone E and De Cosmo S (2021)

Pulmonary Artery Stump Thrombosis:

To Treat or Not to Treat? The Question Is Still Open. Description of a Case

and Review of the Literature.

Front. Cardiovasc. Med. 8:714826.

doi: 10.3389/fcvm.2021.714826

\section{Pulmonary Artery Stump Thrombosis: To Treat or Not to Treat? The Question Is Still Open. Description of a Case and Review of the Literature}

\author{
Antonio Mirijello ${ }^{1 *}$, Mariateresa Santoliquido ${ }^{1,2}$, Pamela Piscitelli ${ }^{1}$, Cristina Borelli ${ }^{3}$, \\ Gaetano Serviddio $^{2}$, Anna Simeone ${ }^{3}$, Elvira Grandone ${ }^{4}$ and Salvatore De Cosmo ${ }^{1}$ \\ ${ }^{1}$ Internal Medicine Unit, Department of Medical Sciences, Fondazione IRCCS Casa Sollievo Della Sofferenza, San Giovanni \\ Rotondo, Italy, ${ }^{2}$ Geriatrics Residency School, Department of Medical and Surgical Sciences, University of Foggia, Foggia, \\ Italy, ${ }^{3}$ Radiology Unit, Fondazione IRCCS Casa Sollievo Della Sofferenza, San Giovanni Rotondo, Italy, ${ }^{4}$ Thrombosis and \\ Haemostasis Research Unit, Fondazione IRCCS Casa Sollievo Della Sofferenza, San Giovanni Rotondo, Italy
}

Pulmonary artery stump thrombosis (PAST) represents a possible complication after lung surgery. We report the case of a 59-year-old man who presented with dyspnoea about 4 years after right pneumonectomy due to squamous cell lung cancer. A CT-scan showed the presence of pulmonary artery stump thrombosis. Although there was no evidence of pulmonary embolism, given the clinical features and radiological shape of the thrombus, anticoagulation treatment with low-molecular-weight heparin was started with improvement of symptoms. The patient was discharged on anticoagulant treatment and a pulmonary CT-scan performed 4 months later showed an almost complete resolution of the PAST. Pathophysiological mechanisms of PAST are still unknown, although several hypotheses have been proposed. However, the decision to treat PAST with anticoagulants is still controversial. A review of literature will be provided in order to discuss risk factors, possible etiologies and to highlight clinical and radiological characteristics that could suggest to treat this condition, in particular when there is an increased risk of complications.

Keywords: anticoagulation, pneumonectomy, pulmonary embolism, thrombosis, pulmonary artery stump

\section{INTRODUCTION}

Pulmonary artery stump thrombosis (PAST) following pulmonary resection for lung cancer is a possible complication after lobectomy (1) or pneumonectomy (2), with an incidence of $12 \%$ (2) after this latter. Generally, PAST occurs early after surgery (3); nevertheless, a delayed presentation has been described, although sporadically (4-10). Pathophysiological mechanisms of PAST are not fully understood, although several hypotheses have been formulated, such as endothelial damage during surgery, hypercoagulability and blood flow stasis in the vascular stump. PAST is generally asymptomatic and incidentally detected at follow-up CT-scans; moreover, it is usually harmless (11). However, in a minority of cases, it could be complicated with pulmonary embolism to the contralateral lung (4), pulmonary hypertension (6) and death (8,12-14). At present, the optimal treatment of PAST is still matter of debate. 
Here we describe the late-occurrence of PAST in a patient treated with right pneumonectomy due to squamous cell lung carcinoma. Clinical features, possible causes and risk factors will be reported. Moreover, a review of the literature will be provided in order to discuss gray areas concerning treatment options and the choice to treat this specific case.

\section{CASE PRESENTATION}

In October 2020, a 59-year-old man was admitted to our Internal Medicine inpatients unit because of the persistence for about 2 weeks of dyspnoea, fatigue, and weight loss. The patient also reported right hypochondrium pain and loss of appetite. Past medical history was relevant for hypertension, type 2 diabetes and alcohol abuse (reported alcohol consumption: 3-5 drinks per day from the age of sixteen). In 2016 he was diagnosed with squamous cell lung carcinoma (stage T4N3M0) and treated with neoadjuvant polychemotherapy (cisplatine + vinorelbin) followed by right pneumonectomy. Despite a history of cancer, he was still an active smoker. His home therapy consisted of insulin and acetylsalicylic acid $100 \mathrm{mg} /$ day.

At admission, blood pressure was $150 / 75 \mathrm{mmHg}$, heart rate 92 bpm, oxygen saturation $94 \%$ in room air, respiratory rate $20 /$ min, body temperature was $36^{\circ} \mathrm{C}$. Physical examination was non-significant apart from hepatomegaly. Results of laboratory tests, including blood gas analysis, at admission are shown in Supplementary Table 1. In particular, acute phase reactants (e.g., fibrinogen, C-reactive protein, ferritin), transaminases, cholestasis enzymes and D-dimer were altered. Hepatitis B and $\mathrm{C}$ markers were negative. Sars-CoV-2 nasopharyngeal swab was negative. Chest X-ray showed opacification and volume loss of right hemi-thorax with consensual mediastinal shift, according to history of previous pneumonectomy; no signs of pulmonary consolidation in the left lung. Abdominal US-scan showed hyperechogenicity of the liver compatible with steatosis and/or fibrosis and biliary sludge. No significant kidneys or spleen abnormalities nor ascites were found. The Esophago-Gastro-Duodenoscopy detected a grade B reflux disease (LA classification), congestive gastropathy and erosive bulb duodenitis. Basing on history, clinical features and Wells' score (0 points) (15), PE was unlikely. An echocardiography showed a normal left ventricle ejection fraction, no right ventricle overload nor pulmonary hypertension. To rule out cancer recurrence, total body CTscan with contrast injection was performed. Chest CT images showed a pulmonary thrombus within the right main artery stump, not present 1 year earlier (Figure 1A). Doppler USscan of lower limbs was normal. Anticoagulant treatment with enoxaparin $100 \mathrm{ui} / \mathrm{kg} / \mathrm{bid}$ was started, together with proton pump inhibitor (PPI). Tests for inherited and acquired thrombophilia were negative as well as antibodies against Sars-Cov-2. Patient's symptoms gradually improved and he was discharged 7 days after PAST diagnosis with anticoagulant prescription. Contrastenhanced CT scan performed 4 months later demonstrated an almost complete resolution of right pulmonary thrombosis (Figure 1B).
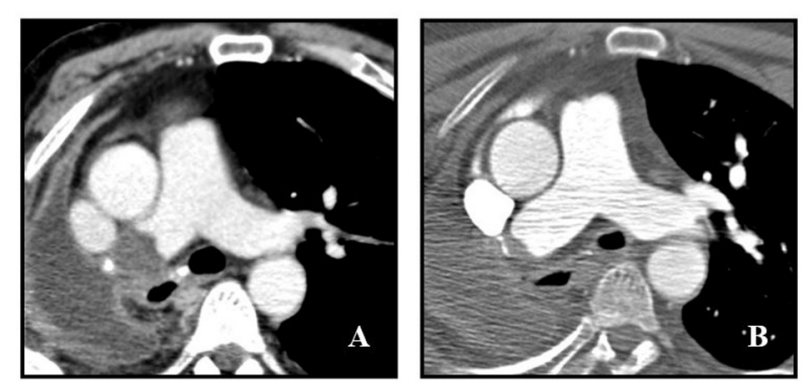

FIGURE 1 | Post-pneumonectomy thrombosis of right pulmonary artery stump. (A) Initial contrast-enhanced CT scan shows a large endoluminal filling defect in the right pulmonary artery stump. (B) Follow up contrast-enhanced CT scan obtained 4 months after (A) shows marked reduction of thrombus size with evidence of a small residual intraluminal defect adjacent to surgical clips.

\section{DISCUSSION}

PAST is a possible complication after lung surgery (2), generally occurring within 12 months (early PAST), even if a delayed presentation has also been described (late PAST) (4-10). Usually it is asymptomatic and incidentally detected during a followup CT-scan (3). However, English literature reports anecdotal cases of patients complaining of dyspnoea finally diagnosed with PAST (Table 1). At present, risk factors and mechanisms at the basis of this thrombotic event are still poorly understood. In a retrospective analysis of 648 oncologic surgeries for primary lung cancer, 25 (3.8\%) PAST were found (3). Among them, elderly age, advanced cancer stage and neo-adjuvant chemotherapy could represent risk factors for its development (3). Regarding pathophysiological mechanisms for stump thrombosis, Virchow's triad has been indicated as one of the possible causes (3). On this connection, three processes could be hypothesized:

1. Endothelial injury during surgery. Complex surgeries and vascular manipulations increase the risk of endothelial damage, reducing the production of fibrinolytic activators with a consequent pro-coagulant state (16). For this reason, the technique with continuous ligature of the stump has been considered more appropriated than the transfixation one, obtaining a regular stump which decreases the probability of PAST. However, this mechanism could be mainly responsible for early PAST.

2. Blood flow stasis of the vascular stump. There is a correlation between stump's length and changes in blood flow dynamics (e.g., blood flow turbulence) (11). Basing on the retrospective revision of chest CT-scans of patients treated with pneumonectomy, Kim and co-workers (2) evidenced that the stump is longer after a right pneumonectomy than after a left pneumonectomy, and the thrombus was more frequently detected in the right (23.3\%) than in the left $(4.6 \%)$ stump. On the contrary Kwek and colleagues (11) found an almost equal incidence of thrombi between right and left stumps. Concerning lobectomy, left-sided thrombi were more common than right-sided one (3). 
TABLE 1 | Cases of PAST reported in the English literature.

\begin{tabular}{|c|c|c|c|c|c|c|c|c|c|c|c|}
\hline References & Gender & Age & $\begin{array}{l}\text { Type of lung } \\
\text { resection }\end{array}$ & Side & Symptoms & Timing & $\begin{array}{l}\text { Lower limb } \\
\text { Doppler US }\end{array}$ & Treatment & Resolution & Complications & Death \\
\hline Barbetakis et al. (22) & Male & 59 & Lobectomy & Right & No & 6 months & Negative & $\begin{array}{l}\text { Heparin, then } \\
\text { OAC for } 6 \\
\text { months }\end{array}$ & Yes & No & No \\
\hline Sato et al. (4) & Male & 73 & Pneumonectomy & Left & Chest discomfort & 8 years & N.a. & Heparin & Yes & $\begin{array}{l}\text { Controlateral pulmonary } \\
\text { embolism (anticoagulant therapy } \\
\text { was discontinued) }\end{array}$ & No \\
\hline Thomas et al. (6) & Male & 51 & Pneumonectomy & Right & $\begin{array}{l}\text { Astenia back pain } \\
\text { dyspnoea }\end{array}$ & 10 years & $\begin{array}{l}\text { Deep venous } \\
\text { thrombosis }\end{array}$ & Heparin & No & $\begin{array}{l}\text { Multiple pulmonary emboli and } \\
\text { pulmonary hypertension }\end{array}$ & Probably \\
\hline Chuang et al. (12) n1 & Female & 29 & Pneumonectomy & Right & $\begin{array}{l}\text { Dyspnoea, } \\
\text { tachycardia }\end{array}$ & 8 months & N.a. & No & No & Infarction left lower lobe & Yes \\
\hline Chuang et al. (12) n2 & Male & 65 & Pneumonectomy & Right & Dyspnoea & $24 \mathrm{~h}$ & N.a. & No & No & $\begin{array}{l}\text { Emboli left lower lobe and } \\
\text { lingular arteries }\end{array}$ & Yes \\
\hline Gorospe Sarasúa (13) & Male & 71 & Pneumonectomy & Right & Dyspnea & 5 month & / & Heparin & No & Death & Yes \\
\hline Akcam et al. (9) & Male & 73 & Pneumonectomy & Left & No & 3 years & Negative & $\begin{array}{l}\text { Heparin, then } \\
\text { warfarin }\end{array}$ & Yes & No & No \\
\hline Joshi et al. (8) & Male & 68 & Pneumonectomy & Right & Pleuric chest pain & 10 years & Negative & $\begin{array}{l}\text { Heparin, then } \\
\text { warfarin }\end{array}$ & No & Yes & Yes \\
\hline Viola et al. (10) & Female & 76 & Lobectomy & Right & Dyspnoea & 6 years & & Rivaroxaban & No & / & No \\
\hline Sawalha and Mador (5) & Male & 67 & Lobectomy & Right & No & 2 years & Negative & $\begin{array}{l}\text { Coumadin for } \\
3 \text { months }\end{array}$ & Yes & No & No \\
\hline $\begin{array}{l}\text { Kotoulas and Lachanis } \\
\text { (23) }\end{array}$ & Male & 53 & Pneumonectomy & Right & No & 3 months & Negative & Acenocumarol & I Yes & No & No \\
\hline Yoon et al. (7) & Female & 75 & Pneumonectomy & Right & Dyspnea & 10 years & N.a. & Warfarin & Yes & $\begin{array}{l}\text { Multiple small thrombi in left } \\
\text { pulmonary artery }\end{array}$ & No \\
\hline Gorospe et al. (14) & NA & NA & Lobectomy & Left & No & 1 year & N.a. & Heparin & Yes & No & No \\
\hline $\begin{array}{l}\text { Dury et al. (24) ( } 3 \\
\text { cases) }\end{array}$ & NA & NA & Pneumonectomy & / & / & / & / & No & / & No & No \\
\hline Wechsler et al. (25) & Female & 72 & Lobectomy & Right & $\begin{array}{l}\text { Shortness of } \\
\text { breath, fatigue }\end{array}$ & 11 months & Negative & No & No & No & No \\
\hline
\end{tabular}


3. Hypercoagulability. Increased platelet count and fibrinogen level at 7 th and 14th day after lung surgery were observed as factors associated with higher thrombotic activity (17). In addition, other factors such as smoking (18), active cancer (19), and sepsis (20) are known to increase blood coagulability. To date, an association between PAST and inherited/acquired thrombophilia has never been described.

The need for anticoagulation in patients with PAST is still matter of debate. According to literature, early PAST is more likely to resolve spontaneously, regardless from anticoagulation, while late PAST usually shows a poor rate of resolution (21).

Among the 17 case reports of PAST reported in the English literature, seven of them were late PASTs (Table 1); all received anticoagulant therapy, the majority of which resolved.

Moreover, anticoagulation could be started according to the morphology of PAST at CT scan. Convex-shaped and floating PAST are considered more acute and at high-risk of embolization to the contralateral lung or of growth. On the contrary, concave-shaped thrombi are considered at lower risk of embolization and more "stable" (11). According to some authors, anticoagulation should be considered for convex thrombi or for a newly occurring PAST in the context of declining pulmonary status (8). Indeed, it is important to understand if PAST represents an in situ thrombosis, a cancer recurrence inside the vascular stump or an embolus from deep vein thrombosis (2); all of these could be indications for treatment. However, the incidence of PAST-associated PE is low (5). According to the available reports, one patient showed contralateral pulmonary embolism (4) and another one showed multiple pulmonary emboli with pulmonary hypertension (6); both of them had been treated, but just one solved (Table 1).

We reported the case of a patient complaining of dyspnoea, fatigue and abdominal pain, and weight loss. Since the presenting symptomatology was not specific for any particular disease, several examinations were performed. Chest X-ray did not show abnormalities in the left lung and, according to Wells' score, pre-test probability of PE was low. Abdominal symptoms and weight loss were consistent with chronic alcoholic liver disease, gastro-oesophagitis and duodenitis. Respiratory symptom was not justified by blood gas analysis, not showing respiratory failure. Finally, chest CT-scan evidenced the presence of PAST. According to CT-scan (Figure 1A), this was a newly evidenced late-occurring PAST with a convex-shaped thrombus in the right pulmonary artery stump with no evidence of PE. These

\section{REFERENCES}

1. Cha SI, Choi KJ, Shin KM, Lim JK, Yoo SS, Lee J, et al. Clinical characteristics of in-situ pulmonary artery thrombosis in Korea. Blood Coagul Fibrinolysis. (2015) 26:903-7. doi: 10.1097/MBC.0000000000000343

2. Kim SY, Seo JB, Chae EJ, Do KH, Lee JS, Song JW, et al. Filling defect in a pulmonary arterial stump on CT after pneumonectomy: radiologic and clinical significance. Am J Roentgenol. (2005) 185:9858. doi: 10.2214/AJR.04.1515 characteristics, in conjunction with the presence of symptoms, surrounding inflammatory state, history of active smoking and previous chemotherapy led us to the decision to start anticoagulation. The CT-scan performed 4 months later found an almost complete resolution of the clot (Figure 1B).

\section{CONCLUSIONS}

PAST represents a possible complication after lung surgery, in particular after right pneumonectomy. Local and systemic factors seem to be involved in its pathophysiology, although the exact mechanisms are not completely understood. Generally, PAST represents an occasional finding at follow-up CT scan and it is asymptomatic; sometimes, patients could complain of dyspnoea, fatigue and chest discomfort. The choice to prescribe anticoagulants should be based on the risk of complications, such as contralateral pulmonary embolism, worsening lung function and death. At present, literature data on factors potentially favoring embolization are few and decision-making algorithms are lacking. It is conceivable that the evidence of convex-shaped thrombi and patient's thrombotic risk could represent the most important factors suggesting the need for anticoagulation. In any case, the choice for optimal treatment duration and follow-up should be evaluated case by case.

\section{ETHICS STATEMENT}

Written informed consent was obtained from the patient for the publication of any potentially identifiable images or data included in this article.

\section{AUTHOR CONTRIBUTIONS}

AM, MS, PP, and EG managed the patient during hospitalization. AM, MS, and PP thought about the study rationale. CB and AS reviewed radiological images. GS and SD reviewed collected data. AM, MS, PP, EG, and SD wrote the first draft. All Authors read, had the possibility to modify and approved the final draft of the paper.

\section{SUPPLEMENTARY MATERIAL}

The Supplementary Material for this article can be found online at: https://www.frontiersin.org/articles/10.3389/fcvm. 2021.714826/full\#supplementary-material
3. Moon MH, Beck KS, Moon YK, Park JK, Sung SW. Incidence and clinical features of the incidentally found vascular stump thrombus during routine follow up after oncologic lung surgery. PLoS ONE. (2017) 12:e185140. doi: 10.1371/journal.pone.01 85140

4. Sato $\mathrm{W}$, Watanabe $\mathrm{H}$, Sato $\mathrm{T}$, Iino $\mathrm{K}$, Sato $\mathrm{K}$, Ito $\mathrm{H}$. Contralateral pulmonary embolism caused by pulmonary artery stump thrombosis after pneumonectomy. Ann Thorac Surg. (2014) 97:1797-8. doi: 10.1016/j.athoracsur.2013.07.102 
5. Sawalha L, Mador MJ. Delayed post-lobectomy pulmonary artery stump thrombosis. Respir Med Case Rep. (2015) 15:368. doi: 10.1016/j.rmcr.2015.04.003

6. Thomas PA, Doddoli C, Barlési F, Reynaud-Gaubert M, Giudicelli R, Fuentes P. Late pulmonary artery stump thrombosis with post embolic pulmonary hypertension after pneumonectomy. Thorax. (2006) 61:1778. doi: 10.1136/thx.2004.028480

7. Yoon HJ, Kim KH, Jeong MH, Cho JG, Park JC. Very late unusual thrombosis of the remnant pulmonary vasculatures after lung resection complicated by embolic events. J Cardiothorac Surg. (2019) 14:1-5. doi: 10.1186/s13019-019-1013-9

8. Joshi M, Farooq U, Mehrok S, Srouji N. Delayed formation of pulmonary artery stump thrombus: a case report and review of the literature. Thromb J. (2009) 7:1-3. doi: 10.1186/1477-9560-7-7

9. Akcam TI, Kaya SO, Samancilar O, Ceylan KC. Pulmonary artery stump thrombosis developed during the late postoperative period. Kardiochirurgia i Torakochirurgia Pol. (2016) 13:260-1. doi: 10.5114/kitp.201 6.62619

10. Viola SR, Costantini PJ, Pugatch RD, Sachdeva A. Anticoagulation treatment of a post-lobectomy pulmonary artery stump thrombus. Am J Respir Crit Care Med. (2017) 195:A6211.

11. Kwek BH, Wittram C. Postpneumonectomy pulmonary artery stump thrombosis: CT features and imaging follow-up. Radiology. (2005) 237:33841. doi: 10.1148/radiol.2371041686

12. Chuang TH, Dooling JA, Connolly JM, Shefts LM. Pulmonary embolization from vascular stump thrombosis following pneumonectomy. Ann Thorac Surg. (1966) 2:290-8. doi: 10.1016/S0003-4975(10)66581-2

13. Gorospe Sarasúa L, Valdebenito-Montecino AP, Muñoz-Molina GM. Pulmonary artery stump thrombus in a patient with right pneumonectomy complicated by bronchopleural fistula. Arch Bronconeumol. (2017) 53:71. doi: 10.1016/j.arbr.2016.11.027

14. Gorospe L, Jover-Díaz R, Muñoz-Molina GM. Bland or tumor pulmonary artery stump thrombosis? Asian Cardiovasc Thorac Ann. (2018) 26:1645. doi: 10.1177/0218492318759351

15. Wells PS, Anderson DR, Rodger M, Ginsberg JS, Kearon C, Gent M, et al. Derivation of a simple clinical model to categorize patients probability of pulmonary embolism: increasing the models utility with the SimpliRED D-dimer. Thromb Haemost. (2000) 83:416-20. doi: 10.1055/s-0037-16 13830

16. Işik F, Kara M, Tunçözgür B, Dizbay Sak S, Erekul S, Kavukçu S. Significance of ligature technique on the formation of pulmonary artery stump thrombosis in a canine model. Acta Chir Belg. (2005) 105:203-6. doi: 10.1080/00015458.2005.116 79700
17. Ichinose Y, Hara N, Ohta M, Hayashi S, Yagawa K. Appearance of thrombosisinducing activity in the plasma of patients undergoing pulmonary resection. Chest. (1991) 100:693-7. doi: 10.1378/chest.100.3.693

18. Leone A. Smoking, haemostatic factors, and cardiovascular risk. Curr Pharm Des. (2007) 13:1661-7. doi: 10.2174/138161207780831347

19. Falanga A, Marchetti M, Vignoli A. Coagulation and cancer: biological and clinical aspects. J Thromb Haemost. (2013) 11:223-33. doi: 10.1111/jth.12075

20. D'Angelo A, Della Valle P, Giudici D, Viganò D'Angelo S. Protein C and coagulation in sepsis. Minerva Anestesiol. (2004) 70:339-50.

21. López-Padilla D, Peghini Gavilanes E, Revilla Ostolaza TY, Trujillo MD, Martínez Serna I, Arenas Valls N, et al. Arterial stump thrombosis after lung resection surgery: clinical presentation, treatment and progress. Arch Bronconeumol. (2016) 52:512-8. doi: 10.1016/j.arbr.2016.07.019

22. Barbetakis N, Asteriou C, Kleontas A. Post-lobectomy pulmonary artery stump thrombosis: how dangerous is it? Ann Thorac Surg. (2011) 91:e44. doi: 10.1016/j.athoracsur.2010.12.037

23. Kotoulas C, Lachanis S. Embolism of the pulmonary artery stump after right pneumonectomy. Interact Cardiovasc Thorac Surg. (2009) 8:5634. doi: $10.1510 /$ icvts.2008.189415

24. Dury S, Toubas O, Delepine G, Deslee G, Lebargy F. Pulmonary artery stump thrombosis following pneumonectomy. Rev Mal Respir. (2007) 24(3 Pt 1):367-70. doi: 10.1016/S0761-8425(07)91071-2

25. Wechsler RJ, Salazar AM, Gessner AJ, Spirn PW, Shah RM, Steiner RM. CT of in situ vascular stump thrombosis after pulmonary resection for cancer. Am J Roentgenol. (2001) 176:1423-5. doi: 10.2214/ajr.176.6.1761423

Conflict of Interest: The authors declare that the research was conducted in the absence of any commercial or financial relationships that could be construed as a potential conflict of interest.

Publisher's Note: All claims expressed in this article are solely those of the authors and do not necessarily represent those of their affiliated organizations, or those of the publisher, the editors and the reviewers. Any product that may be evaluated in this article, or claim that may be made by its manufacturer, is not guaranteed or endorsed by the publisher.

Copyright (C) 2021 Mirijello, Santoliquido, Piscitelli, Borelli, Serviddio, Simeone, Grandone and De Cosmo. This is an open-access article distributed under the terms of the Creative Commons Attribution License (CC BY). The use, distribution or reproduction in other forums is permitted, provided the original author(s) and the copyright owner(s) are credited and that the original publication in this journal is cited, in accordance with accepted academic practice. No use, distribution or reproduction is permitted which does not comply with these terms. 